\title{
EL PAPER DE LA DONA A LA PUBLICITAT: LA MANIPULACIO D'UNA IMATGE
}

\author{
Joan Estruch \\ Francesc Mercadé \\ Jordi Romeu \\ (Universitat Autònoma de Barcelona)
}

Aquest article és el fruit del treball dut a terme en un seminari de sociologia durant el curs 1977-713. A partir de l'anàlisi d'una mostra d'anuncis publicitaris diversos, però que tenen com a denominador comú la presència de la dona, hom intenta veure quin és l'estereotip de la dona vehiculat per la publicitat. L'elaboració d'un codi de classificació permet de situar la dona dels anuncis en diferents etapes de la seva vida $i$ en l'exercici de papers diversos: nena, noia, esposa, mare, mestressa de casa, dona en el treball i dona amant. Però en aquesta diversitat de situacions no hi ha mai contradicció, sinó un model coherent i únic: la nena i la noia són ja dones, $\mathrm{i}$ les dones continuen essent sempre criatures; casolana encara que treballi la dona és simultàniament espo: $; a$, mare $i$ amant. Les dues característiques fonamentals d'aquest estereotip de la dona als anuncis publicitaris són, d'una banda, la constant accentcació de la seva dimensió eròtica i sexual i, de l'altra, la seva sistemàtica subordinació a l'home. D'aquesta maneta Ia publicitat acompleix una doble funció, de reproducció de la ideolugia dominant, $\mathrm{i}$ de legitimació $\mathrm{i}$ reforçament d'aquesta mateixa ideologia. 


\section{Introduccio}

Una simple mirada als mass media ens fa adonar immediatament de la importància de la publicitat. Quantitativament la seva presència és abassegadora: a la lletra impresa, a les ones, pels carrers. En termes de rendabilitat econòmica, la publicitat esdevé fonamental: la premsa escrita, els diaris $i$ les revistes en depenen per a la seva supervivència; les cadenes privades de ràdio en depenen igualment; la televisió en viu (en certa manera la TVE és tota ella un immens spot pujlicitari); fins i tot al cinema hi és present. La publicitat, per tant, arriba a tothom. Hi arriba cada dia, constantment, amb independència del fet que hom s'hi fixi o no; ja fa temps que Packard demostrà que l'efcècia de la publicitat no depenia pas del fet que hom s'hi fixés. ${ }^{1}$

Però si una mirada als mais media ens fa adonar de la importància de la publicitat, una mirada a la publicitat ens fa veure immediatament la importància del paper que hi jug a la dona. La seva presència als anuncis és gairebé constant; en diferents tacetes i sota aspectes diversos, però pràcti. cament sempre en relacio amb l'home. La publicitat sol accentuar de manera notable $i$ ostentosa la dinensió sexual de la feminitat. La publicitat sembla, segons com, I'hereva directa d'aquella teologia escolàstica que es mirava la dona com una mulies, tota sexus.

Si la dona apareix a la publicitat com una mulier tota sexus, hom pot suposar sense por d'equivocar-se que la presència i la presentació publicitàries de la dona establiran -iraplícitament o explícita - una jerarquització dels sexes, en la qual a la dor a li correspondrà de jugar sistemàticament un paper de subordinació.

1. Vance Packard, The Hidden Persuaders (1957) (Hatmondsworth: Penguin Books, 1960). 
Fou a partir d'aquestes consideracions inicials que ens plantejàrem la possibilitat de fer - al si d'un seminari de sociologia a la Universitat Autònoma de Barcelona durant el curs 1977-78 - un estudi monogràfic sobre el paper de la dona als anuncis publicitaris. Desptés de precisar el marc de teferència en què se situa l'anàlisi i d'explicitar breument la metodologia del treball, donarem compte aci dels resultats obtinguts.

\section{Aproximació teòrica}

La publicitat té com a funció declarada la d'informar i donar a conèixer uns determinats productes. A partir d'ací es pot bastir tot un discurs racionalitzador: es tracta d'aconseguir que el consumidor tingui una orientació, es pretén ajudar-lo a escollir, es vol que pugui satisfer de la millor manera possible les seves necessitats. Obviament, però, darrera aquestes raons se n'amaguen d'altres. La funció real de la publicitat (funció latent, si es vol) és la de fer vendre els productes, incrementant els beneficis. Més que de donar a conèixer els productes, del que es tracta és d'induir a llur consum. El problema no és tant el d'ajudar el consumidor a escollir, sinó el de forçar-lo a triar; és a dir, el d'obligar-lo a consumir. L'objectiu no és tant el de satisfer les seves necessitats sinó el de crear-les-hi.

La publicitat, tal com la coneixem a les societats capitalistes, cal emmarcar-la en el context de l'anomenada societat de consum. L'economia de mercat porta a la publicitat dels sabons o de les colònies quan s'estableix una competència entre diferents subministradors de productes fonamentalment idèntics, $\mathrm{i}$ que sols es poden distingir per Ilur diferenciació marginal. Això és important en el cas concret que ací ens ocupa, perquè vol dir que si el que distingeix els diversos productes és l'embalatge, la dona de l'anunci publicitari formarà part d'aquest embalatge. Però funs i tot allí on no hi ha aquesta competència directa entre productes similars, la publicitat segueix essent necessàtia en la mesura en què, com dèiem $f a$ un moment, allò de què es tracta és de fer vendre i de crear necessitats. De tal manera que seria fals imaginar que la publicitat és quelcom de circumstancial en el sistema capitalista: no és circumstancial, sinó estructural.

Centrant-nos en el tema concret del paper jugat per la dona a la publicitat, creiem que l'anàlisi ha de tenit en compte els següents elements:

1. La publicitat no és creadora d'ideologia, sinó que el que fa és reproduir la ideologia dominant. Per tant, la diferenciació que estableix entre els papers de l'home i de la dona no ha d'ésser fruit de cap mena de 
diferenciació «natural», sinó que és comprensible dins la lògica diferencial i diferenciadora del sistema. ${ }^{2}$ Conseqüència d'això és que des d'un punt de vista sociològic la crítica de la publicitat no es pot fer des del terreny de la mateixa publicitat: s'ha de fer des del terreny de la ideologia. En aquest sentit el nostre treball hauria d'ajudar a comprendre uns determinats aspectes d'aquesta ideologia.

2. La publicitat no defineix de traneta tigotosament vàlida els productes, però tampoc no en crea falses definicions. El que succeeix és precisament que no els defineix. Dit d'una aitra manera: el discurs de la publicitat és un discurs tautològic i absolutament inverificable, sense sentit lògic. Així, per exemple, en un anunci de rellotges d'or per a senyora, el text comença dient: «El oro, esa quimera forjada en el yunque femenino de los sueños.» Per tal de predisposar favorablement el potencial consumidor, la publicitat no defineix el producte sinó que en presenta una mostra exemplar en un marc encantado:.. ${ }^{3}$ El missatge implícit és que comptant el producte es retrobarà igualment l'element encartador: no té tes d'estrany, doncs, que aquest element encantador sigui sovint la presència d'una dona jove i atractiva.

3. La publicitat no recorre a la realitat, sinó al seu estereotip. En el nostre cas, per tant, això vol dir que reproduità estereotipades -és a dir accentuades, com en una caricatura-- les diferències masculí-femení, ${ }^{4} \mathrm{I}$ que presentarà la dona segons els sevs papers més clàssics, tant tradicionals com moderns. En efecte, el recurs a l'estereotip significa que la publicitat parlarà menys de la dona real que de la mitologia de la dona. Una mitologia que evoluciona de la dona tracicional (mestressa de casa) a la dona moderna, alliberada o suposadamer.t alliberada. Al centre d'aquest espectre hi tindrem avui allò que Lorée anomena precisament el mite de la dona moderna: a la vegada esposa, rrare, i seductora. ${ }^{5}$

4. La publicitat no empra -malgrat les aparences- un discurs

2. Jean Baudrillard, La société de consommation (1970) (París: Gallimard/Idées, 1976).

3. Aquest mateix marc és fictici: en els anuncis publicitaris que analitzarem hi dominen els interiors urbans luxosos, així com els exzeriors «naturals». Es tracta d'una natura «de Llauna», no un medi de vida, sinó un medi d'espiai per a la gent de ciutat, que hi acudeix mudada, amb cotxes, motos, bicicletes, taules i transistors, convertint així el camp en un nou intetior urbà.

4. Sobre la caricatura de Jes diferències masculi-femení, Georges Falconnet i Nadine Lefaucheur, La fabrication des mâles (París: Seuil, 1975).

5. Marguerite Lorée, «L'image de la fernme dans la publicité nord-américaine et française", a Andrée Michel, Femmss, sexisme et sociétés (París: PUF, 1977), pàgines $135 \mathrm{i}$ ss. 
racional. $\mathrm{O}$, millor dit, la coherència del discurs publicitari no es $f a$ a nivell de la consciència sinó a nivell del subconscient: el nivell de les pulsions que ens mouen $i$ dels blocatges psicològics que ens refrenen. En aquest context, i per a illustrar millor el que volem dir, creicm que la literatura i el cinema eròtics constitueixen un exemple paradigmàtic d'aquest fenomen. Posem per cas les escenes gairebé obligades de lesbianisme i de masturbació femenina a les pellícules del gènere, i que no són en el fons sinó un mitjà de satisfacció dels fantasmes voyeuristes de l'home (darrera precisament una falsa aparença d'emancipació sexual femenina). L'anomenada pornografia de les nostres latituds no fa sinó presentar una dona sexuaiment activa, però amb una sexualitat reduïda a la seva dimensió orgàstica masculina. ${ }^{6}$ La dona del cinema eròtic és exactament la-dona-queejacula. I en aquest sentit - més enllà fins i tot del discurs sobre la donaobjecte-cal veure en aquesta literatura i en aquest cinema una forma sofisticada de «masclisme». Una forma de masclisme paradoxalment consagrada per Wilhelm Reich, que sota un plantejament aparentment revolucionari de la sexualitat no fa sinó ensarronar la dona, reduint la seva sexualitat a unes categories exclusivament genitals i masculines.

5. Cal preguntar-se el perquè del lligam entre la publicitat i la dona, que és més aviat - -i més exactament-- un lligam entre la publicitat i el cos-de-la-dona. En el culte al cos i al plaer corporal dels anuncis de vestits, productes de bellesa, perfums, joies, etc., creiem retrobar-hi l'actual mitologia del cos com objecte de consum primordial. Assistim, com dirà Baudrillard, a un autèntic «investissement narcissique du corps»:" el cos bell, el cos cuidat, el cos net, el cos saludable. Fil ha en la nostra societat una percepció espectacular i narcissista del cos, fenomen que es manifesta a bastament en tot el que té relació amb la moda. En definitiva, és doncs el cos esdevingut ocasió i pretext de consum el que estableix el lligam entre la publicitat i la dona ${ }^{8}$

6. Finalment, cal analitzar la funció de la publicitat en general dins el context del procés de socialització $\mathrm{i}$ integració de l'individu en un ordre social determinat. La publicitat, efectivament, mai no fomentarà la

6. «El que m'agrada de les noies de les pellícules pornogràfiques és que són iguals que els homes: sempre tenen ganes de fer l'amor», diu un afeccionat al cinema pornogràfic; citat per Pascal Bruckner i Alain Finkielkratut, Le nouveau désordre amouretux (Paris: Seuil, 1977), p. 69. També als nostres anuncis veurem que un dels elements dominants és precisament el de la dona oferta, disponible, «sempre a punt».

7. Jean Baudrillard, op. cit, p. 200.

8. Jean Maisonneuve, «Le corps et le corporéisme aujord'hui», Revue Française de Sociologie, vol. XVII (1976), p. 565. 
discussió, la reflexió o la crítica: l'únic que estimula és el consens. La publicitat nega el conflicte i la díerència per «imposar un consens».' Així doncs, la inatge de subordinació de la dona transmesa per la publicitat legitima la seva discriminació en la vida real: en el treball, a casa, en el sexe. En oferir un model de distribució del poder entre home i dona, els anuncis publicitaris tefecteixen el que passa en tealitat. Reprodueixen la tealitat, i la reprodueixen de manera estereotipada. Però, a la vegada, dialècticament, la publicitat reforça i legitima així aquesta desigual distribució de poder.

Partint del fet que la distribució de poder entre ambdós sexes a la nostra societat és desigualitària (seria irònic dir-ne una hipòtesi de treball per comptes d'un fet), l'interès ćel nostre estudi és el de permetre'ns d'estudiar exageradament a la publicitat un fenomen que condiciona l'exagetada realitat, a la vegada que n'is un reflex.

\section{Notes metodologiques}

Fou, doncs, a partir d'aquest marc de referència general que ens plantejàrem el treball concret a dur a terme. Es tractava d'examinar els diferents papers jugats per la dona en els anuncis publicitaris; és a dir, d'analitzat els estereotips sobre la dona vehiculats per la publicitat; de veure quina era la imatge transmesa de la don:a, reflex d'una realitat social que oposa l'home i la dona, i que a la viegada contribueix a crear socialment uns caràcters $i$ unes qualitats de les persones que donen lloc a la contraposició de l'estereotip masculí $i$ el femer:1. ${ }^{10}$

El món dels anuncis publicitaris que aci estudiarem és en definitiva un món que gira entorn de l'home: de l'home, de la seva dona, de la seva familia. La dona $\mathrm{i}$ la família apiareixen efectivament com el primer camp de poder de l'home. La publicita:, en la seva illusòria negació del conflicte, crida a exercir el poder sobre el; objectes. I en bona part també sobre la dona i la farnilia, considerats scivint com objectes (utilitatis, de consum, de prestigi) de l'home. La publicitat esdevé així una empresa encantadora i mistificadora: intentant fer oblidar la dominació a la qual l'home està sotmès en la seva vida social, i 'a seva manca de poder real, la publicitat crea la illusió de domini i de porler.

El material de la nostra anàlisi el constitueixen anuncis publicitaris

9. Jean Baudrillard, op. cit., p. 192.

10. Com es palesa en el fet qut: segons si es pretén vendre un mateix producte a l'home o a la dona, la publicitat et farà ressaltar característiques diferents. 
de diferents revistes espanyoles dels darrers anys. ${ }^{11} \mathrm{La}$ tria de les revistes com a objecte d'estudi, en comptes d'altres mitjans de comunicació, obeí simplement a un criteri funcional de major facilitat d'accés, de recoliida, i fins $\mathrm{i}$ tot de reproducció. El mateix criteri explica que ens limitéssim voluntàriament a revistes espanyoles, tot $i$ que en diferents moments hem utilitzat igualment una mostra nombrosa (però recollida de manera no sis. temàtica) d'anuncis de revistes estrangeres, particularment alemanyes i franceses, per tal de comparar-los, primer, amb els nostres, i per verificar, més tard, que el nostre codi intexpretatiu pogués aplicar-s'hi igualment.

Es féu així una recollida sistemàtica d'anuncis de revistes que comportessin una fotografia en la qual aparegués la dona, tant si era sola, com amb l'home o un fill, com en grup, etc. Si bé la presència d'una fotografia fou considerada (amb alguna rara excepció) com un requisit indispensable, és evident que l'anàlisi dels anuncis tingué posteriorment en compte tant la inatge com el text que l'acompanya.

En definitiva, hem treballat així sobre un total de 128 anuncis, alguns dels quals apareixen reproduits aci, a tall d'exemple, per a illustrar el text. Esquemàticament, el procediment de treball fou el següent: una vegada recollit el material, fou primer analitzat separadament $i$ de manera individual per cadascun dels tres autors, en un intent de descripció i anàlisi de contingut dels anuncis. Aquestes anàlisis individuals foren després contrastades i discutides conjuntament, fins arribar a l'elaboració d'una fitxa única per a cada anunci. En l'etapa següent el material fou examinat novament (segons el mateix procediment de treball individual primer $i$ discussió conjunta després) amb el fi d'arribar a establir un codi de classificació dels anuncis en diverses categories. Finalment, en una tercera fase i una vegada establert ja aquest codi, un darter examen de cada anunci permeté d'atribuir-li la seva categoria corresponent. La Taula I reprodueix el codi, amb les seves diferents categories i subcategories, i amb la indicació del nombre d'anuncis classificats en cadascuna d'elles.

11. Les revistes són les següents: Ama, Cambio 16, Cuadernos para el Diálogo, Diez Minutos, Dunia, Hola, Intervitu, Lecturas, Lui, Nuevo Estilo, Pentbouse, Personas, Por Favor, Reporter, Sábado Grático, Semana, Ser Padres, Telva i Triunto. 


\section{TAULA I}

Codi i distribució de la mostra

1. NENA

1.1. Coqueta, presumida $\ldots \ldots \ldots \ldots \ldots \ldots \ldots \ldots . . . \ldots$

1.2. Futura dona ............................. 4

1.3. Espontània .............................. 1

2. NoIA

2.1. «Lliure i emancipada» ...................... 6

2.2. Promesa, futura esposa ..................... 4

2.3. Enjogassada ............................... 4

2.4. Infantil ................................. 317

3. EsPOSA

3.1. Feliç, satisfeta, examorada .................. 5

3.2. Dòcil i sotmesa ............................. 2

3.3. Objecte de prestiygi de l'home ............... 5

3.4. Fràgil i delicada ........................... 113

4. MARE

4.1. Orgullosa i cofoia del seu fill $\ldots \ldots \ldots \ldots \ldots \ldots, 1$

4.2. Atenta, que viu per als altres ................ 2

4.3. Educadora .................................. 25

5. Mestressa de casa

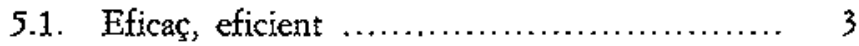

5.2. Bona administradora, estalviadora ........... 4

5.3. Casolana .................................. 8

5.4. «Liture i emancipada» ..................... 2 17

6. FEINA

6.1. Subordinada ............................... 2

6.2. Ensenyada, aprerent ...................... 1

6.3. Eficient, bona coll aboradora ................ 2

6.4. Objecte de prestigi i admiració ................. 1

6.5. «Emancipada» ............................ 2 
7. AMANT

7.1. Misteriosa, llunyana ......................... 3

7.2. Que fa goig, que vol ésser seduïda .......... 15

7.3. Que provoca, que excita, que sedueix ........ 6

7.4. Disponible, que s'ofereix ................... 10

7.5. Admirativa respecte al mascle ................ 3

7.6. Fràgil, que necessita protecció ................ 4

7.7. Joguina sexual del mascle .................... 1

7.8. Enjogassada, despreocupada, inconscient ..... 4

7.9. Que s'autocomplau ......................... $8 \quad 54$

8. OBJECTE DECORATIU

8.1. Objecte decoratiu

El codi elaborat pretén classificar en cada cas els anuncis segons el paper principal jugat per la dona en cadascun d'ells. És important de fer observar que aquests diferents papers no són en definitiva mai contradictoris, de tal manera que l'estereotip de la dona vehiculat per la publicitat seria en realitat la suma de tots ells. Tractarem ara, però, de fer una síntesi dels elements dominants que apareixen en cadascuna de les categories.

\section{La dona-nena}

La nena és sovint presentada en els anuncis com una imatge del que ha d'ésser la dona. És una dona en petit, amb totes les «qualitats» que ha de posseir la dona adulta, de la mateixa manera que la dona no deixarà mai del tot d'ésser una nena. Les dones són com nenes, les nenes són ja dones. Per ésser sempre "ella mateixa» la dona ha d'ésser com quan era nena, ha de continuar essent-ho (vegeu foto num. 8).

Com la dona, per tant, la nena és ja presumida, coqueta, espontània. La nena (foto núm. 1) és «petita però gran», $\mathrm{i}$ està ja «plena d'admiradors». La nena és presentada així com una prefiguració dels papers clàssics de la 
dona: és una futura esposa, futua mare, futura mestressa de casa, i futura amant. Aquest fet és particularment patent en aquells anuncis on apareixen a la vegada el nen i la nena. La distribució que s'hi fa dels papers masci¿i/femení és una perfecta reprodicció dels estereotips més clàssics que més endavant retrobarem en molts 'Sels anuncis, en què els personatges són adults. Així el nen, futur propietııi i posseidor, és el qui pren les iniciatives $i$ les decisions, telegant la nena al paper bàsicament passiu i subordinat al qual està destinada. "Quan sigui gran - diu el text d'un dels anuncis més descarats en aquest sentit- et compraré un nen» (núm. 2).

\section{La dona-noia}

Hem inciòs en aquesta cattgoria els anuncis que presenten noies situades en una etapa intermèdia entre la infantesa $i$ la dona adulta, $i$ que estan desprovistos de connotacicns sexuals directes. Altrament, si anuncis de noies de la mateixa edat tenien aquestes connotacions, han estat classificats a la categoria de la dona - amant.

La noia apareix així com l'esbós de la dona que ha d'esdevenir en un moment del temps ja moit proper. És sovint una noia infantil $i$ enjogassada (núm. 3), que troba molt «divertit triar»: triar colors de jerseis $i$ colors de nois diferents, i que gaudeix escollint el negre durant una estona. Es la noia alegre, despreocupada (núm. 6), per a la qual la vida segueix essent un joc, com a la infància, en què l'home, con a l'edat adulta, la protegeix, l'ensenya, $i$ en definitiva la domina. És també, per tant, la noia que traduità la necessitat de protecció i la situació de dependència en el seu prometatge: la noia enamorada, futura esposa, lliurada ja a l'home totalment i definitiva, tal con s'encarregaran de recordar-nos-ho els obsequis de diamants, «símbol d'un compromís per a sempre» (núm. 5).

Què és el que separa aquesta noia i la nena, que era tarnbé ptesentada coma una prefiguració de la dona? La diferència és que Ia noia ja té la regla: «la manifestació de la feminitat és un problema de cada mes», diu un anunci de tampons per als dies de la menstruació (una altra marca afegirà: «et desitgem una regla feliç»). A la vȩ̣ada, però, la noia es distingeix de la dona pel fet que encara és verge. Per a ella, tot el que fa referència al sexe és encará una incògnita, un tabú. Per això no sap què fer quan li arriba el dia en què per primera vegada se li «manifesta la feminitat»: la mare es veurà obligada a ajudar-la (núm. 10) donant-lí una «pura informació higiènica que gairebé no té res a veure amb el sexe».

Petò no tots els anuncis de la noia volen tenir una aparença tan innocent i tradicional. Creant una suposada alternativa, els que es creuen més 
avançats introdueixen la idea d'una lifbertat i una emancipació aparents (núm. 4). Es tracta aleshores de noies «que han canviat», «lliures $i$ independents», que «pensen i decideixen pet elles mateixes», i que ja «no suporten aquells perfums $\tan$ femenins $i \tan$ convencionals d'ahir». La matca de l'anunci en qüestió té cura, de tota manera, que aquesta nena «nova», «lliure», «independent» no es quedi sense el seu perfum. Jugant amb la moda de la pseudo-ideologia d'una dona nova i lliure, la publicitat pretén recuperar així el discurs per a seguir proposant el mateix de sempre: el recurs al perfum amb l'olor del qual la dona ha de continuar atraient el mascle, tot afirmant que es tracta de l'«aroma de la nueva mujer».

\section{La dona-esposa}

El paper d'esposa és un dels papers clau de la dona a la societat mo derna, $i$ per tant també a la publicitat. Trobem ací el mite de la dona moderna, a la vegada esposa, mare i seductora. ${ }^{12}$ D'alguna manera, doncs, el paper d'esposa engloba els altres: és el comú denominador de la donamare, de la mestressa de casa i, sovint també, de la dona - amant.

L'esposa és normalment presentada com la dona plenament realitzada, aquella que ha assolit el seu ideal, que ha aconseguit els objectius fixats des de la infantesa. Per això l'esposa és una dona satisfeta i feliç: però feliç sobretot en la mesura en què és capaç de fer feliç l'home, el marit (núm. 7), en la mesura en què sap jugar el seu paper correctament, responent a les expectatives d'ell. Per consegüent la felicitat d'aquesta esposa enamorada comporta al mateix temps una clara dimensió de submissió al marit.

Fràgil i necessitada de protecció, la dona és dòcil envers el marit $\mathrm{i}$ se subordina a ell $i$ al seu poder. Aquesta subordinació es manifesta de forma exagerada $i$ caricaturesca en subratllar (núm. 9) que tot i que es tingui «una dona, i una sola, i per a tota la vida» (amb la qual cosa l'anunci recorda, de passada, els esquemes culturals de la moral dominant: monogàmia $\mathrm{i}$ indissolubilitat del matrimoni), aquesta dona ha d'ésser l'equivalent funcional de tot un harem que ompli d'atencions «el moro». Doncs «el moro" és, per a l'home occidental, el model inassolible del poder absolut sobre la dona, i de la submissió o l'esclavitud total d'aquesta en mans de l'home. A fi que Ia dona única «li duri» més, l'home haurà de preocupar-se d'oferir-li els complements electrodomèstics adequats (amb la qual

12. Nota núm. 5 . 
cosa l'anunci recorda, de passada, que les feines de la casa són qüestió de la dona).

Sotmesa al seu marit, l'esposa n'és propietat. És, com si diguéssim, una partida del seu actiu comptable. I com a tal objecte de propietat a la dona li cal mantenir el seu valor, lluitant contra les amenaçants devaluacions de l'ús i del temps. Caldrà, per tant, que la dona tingui cura de les seves facultats i sobretot d'allò que en darrer terme constitueix el seu únic capital: el cos. «Sentir-se bella és per a la dona una font de plaer; per al seu marit, aquesta és una sensació agradable»: fer més bonica la seva dona —enjoiant-la - serà per a l'home «motiu de felicitat» (núm. 11).

L'esposa esdevé així un objecte de prestigi de l'home, un símbol de status un motiu de satisfacció. El marit podrà sentir-se prou cofoi de les seves possessions com per a presumir-ne i fer-rte ostentació. I què millor, per tant, que una fotografia de sus cbicas (esposa i filla) per a demostrar de manera concloent que el seu orgull no és injustificat? (núm. 13). I és que, com diu l'anunci en qüestió, «quan hom té unes noies així... no n'hi ha per menys»!

\section{La dona-mare}

Però si l'home se sent crgullós de la seva esposa, fins el punt de fer-ne ostentació, la dona se sant orgullosa de la seva família, de la qual ella és el centre simbòlic. Si en el seu paper d'esposa la dona es defineix en relació al marit, en el seu paper de mare es defineix en canvi en relació a la familia. Així, tot prepara at el menjar con li correspon (núm. 1), la «mamà no aconsegueix dissimulat el lògic orguil de tenir una familia tan cinematogràtica», una família e. la qual cadascú juga a la perfecció el paper que pel sexe i l'edat té assignat.

De tota manera, als anuncis publicitaris el paper de mare no és subratllat, sinó que apareix com a relativament secundari. La mare, cofoia dels fills que ha donat al marit, se n'ocupa $i$ els omple d'atencions, $i$ en algun moment els educa. Aquesta cducació, però, té un pes específic poc im. portant $i$ es limita a qüestions de sentit comú, a feines de la casa, o a afers que toquin de lluny (i només de lluny) el tema del sexe. Com quan (num. 10) la mare instrueix li seva filla --nena i futura dona- de manera «senzilla», «normal», superant «el pes de segles i segles de tabús inconcebibles»... sobre la manera de collocar-se una compresa higiènica. 
El tol de mestressa de la casa (que en l'expressió castellana ama de casa té totes les connotacions adients de dona a la vegada mestressa $\mathrm{i}$ serventa) és un complement dels dos anteriors i situa la dona en l'únic terreny on li són admesos un cert poder i una capacitat de decisió. La seva tasca és «valorada» com eficient: bona administradora de l'economia domèstica (dels diners del marit), la dona té en la casa el seu lloc d'autonomia.

La casa és el món de la dona; la cuina serà literalment «la millor habitació de casa sevà (núm. 14). La bona ama de casa estimarà per tant aquest món seu: serà una dona casolana, una dona que es realitzarà ella mateixa en les feines de la casa. Perquè, efectivament, fer les tasques casolanes és «realitzar queicom per als altres; és oferir el millor d'una mateixa; és saber comprar, saber treballar, i saber donar; i és saber-ho fer amb amor» (núm. 12).

Habitualment aquest estereotip de la dona casolana és l'expressió del paper més clàssic de la dona: bona esposa, bona mare de família, bona mestressa de la casa. La moral tradicional de la vocació casolana de la dona troba ać el seu darter refugi. En alguna ocasió, però, la publicitat vol trencar aquest esquema ( $i$ oferir per tant una nova motal); si la dona aconsegueix racionalitzar la feina de la casa, si aconsegueix reduir el temps necessari per a complir amb les seves obligacions (sus labores), aleshores podrà permetre's el luxe de sortir parcialment d'aquest tmón. Però tampoc en aquest cas ho serà per a fer coses «serioses»! com diu l'anunci d'una màquina de rentar plats que es proposa «que tu siguis cada dia més persona», perquè «tu no ets un electrodomèstic ni tens catorze programes de rentat»; tens coses millor per fer, $\mathrm{i}$ aquestes coses són «estudiar, treballar a fora, sortir, entrar, conèixer, viure..., realitzar-te», una manera perfecta de futilitzat tot el que la dona pugui fer fora de casa (núm. 16).

\section{La dona a la feina}

Tot $i$ que no hi tecorren amb frequiència, els anuncis publicitaris presenten de tant en tant la dona en el context de la feina fora de casa, en l'exercici d'una ocupació determinada. Però encara que es tracti en el nostre codi d'una categotia ben diferenciada de totes les altres, no hi ha en el paper jugat aquí per la dona oposició ni contradicció amb eís seus papers més habituals. Ben al contrari, els anuncis no fan en aquest cas altra cosa que teforçar la desigualtat de les relacions entre la dona i l'home. 
La dona està típicament en situació d'aptenentatge o en tot cas de subordinació. La secretària eficient, sota les otdres de l'alt executiu, n'és un exemple paradignàtic (num 15). $\mathrm{O}$ bé juga el paper d'objecte d'admiració, de prestigi de l'empresa, tant per la seva aparença física com pel fet de tenir cura dels detalls que facin més agradable la feina de l'home: sota la forma d'azafata (núm. 15), és el charme d'un avió programat per homes, pilotat per l'home, i que serveix per a transportar homes importants.

Hi ha als anuncis una clara diferenciació entre els treballs considerats masculins $\mathrm{i}$ els femenins. La propaganda de cursets de formació professional, per exemple (núm. 17), s'adreça a l'home per a feines com: informàtica, marketing, banca, comptabilitat, agricultura, judo, organització administrativa i electrònica. I a la dona per a: idiomes, mecanografia i taquigrafia, secretariat, bellesa, puericultura, i tall i confecció.

La situació laboral de la dona és òbviament el terreny privilegiat per a fer afirmacions sobre la seva "emancipació» i independència. Però planteja al mateix temps la qüestió del conflicte entre la professionalitat i els papers tradicionals de la dona, centrais en la casa i la família. «No ho deixaré pas córrer tot només pel meu embaràs», diu la dona que traballa (número 18), la dona "moderna» que es realitza en la seva feina. Però fins i tot pet a aquesta dona la feina és quelcom que «absorbeix bona part del seu temps», sense que això l'excusi de dedicar la resta del temps a les feines familiars de la casa. El suposat «alliberament» de la dona, a la publicitat no acaba de ser-hi.

\section{La dona - amant}

De tots els papers de la dona als anuncis publicitaris, el més important és sens dubte el d'amant. Fins i tot quan és esposa o quan és mate, la dona segueix essent amant. Pròpiament hem classificat en aquesta categoria tots els anuncis en què es sulsratllava bàsicament la dimensió eròtica $\mathbf{i}$ sexual de la dona. No és doncs casual que sigui aquesta la categoria en la qual els anuncis són més nombrosos, indici que tot el que fa referència al sexe i a la seva repressió és un camp adobat de la cultura actual i també, per tant, de la publicitat.

Un primer element de la dimensió eròtica de la «feminitat» anbo què juguen els anuncis publicitaris ési el de la inaccessibilitat de la dona, objecte de desig però inassolible. Llunyana i misteriosa, «la dona és una illa» verge i exòtica (núm. 19) que cal explorar i conquerir. És una dona en certa manera irreal, producte dels sominis i els fantasmes de possessió de l'home. 
Habitualment, però, no és aquesta dimensió de misteri i llunyania la que la publicitat tendeix a subtatilar, ans al contrari. El més freqüent és l'anunci de la dona ben real, físicament ben present i atractiva: la dona bonica, elegant, maquillada; la dona que fa goig (ct. per exemple núm. 20). Es igualment la dona seductora i que a la vegada vol ser seduida: la dona guapa que no vol falses «innocències», sinó que espera que l'home «sigui més atrevit» (num. 22).

Un pas més enllà, un grau més en l'escalada de l'aparent proximitat - accessibilitat de la dona, $i$ aquesta no és ja tan sols atractiva, sinó que adopta una postura provocativa, com si fos l'home -tot home, tot lector de la revista- l'objecte del seu desig sexual (num. 23). Es la dona que ja ha secuitt l'home $i$ ha estat seduida per ell (num. 25). La dona que predica la bona nova que «el sexe no és pecat», tot i que encara segueixi essent «un vici», però «un vici heroic $\mathrm{i}$ intełligent» (núm. 21). En aquesta nova orientació - -que és de preveure que esdevingui cada vegada més freqüent als anuncis publicitaris, a través de la progressiva introducció del cos nu i del discurs declaradament eròtic- fa tota la impressió que la persistència de l'estereotip masculí/femení és garantida; en els mateixos termes de l'anunci (núm. 21) l'home hi posarà «l'heroüsme i la intelligència», i la dona hi posarà «el vici».

Un doble anunci d'un mateix producte, en el qual l'única diferència radica en un intercanvi dels papers masculí i femení (núms. 26 i 27) és ben illustratiu d'aquest manteniment de l'estereotip, i de la persistència de la desigualtat en la distribució de poder entre home $i$ dona: davant l'impuls sexual thome, en posició dominant, és aquell que "resisteix o no resisteix»; la dona pel seu cantó, en eterna posició subordinada, és la que «cedeix o no cedeix».

En eis anuncis que posen més clarament de manifest aquesta dimensió sexual de la dona - mant, aquesta apareix així com la dona oferta, disponible, la dona que està sempre a punt per a l'home (ním. 24). Aquesta disponibilitat farà d'ella, però, un cop efectuada la conquesta, un trofeu més en l'historial amorós de I'home. Algun anunci (num. 28) és absolu* tament explícit en aquest sentit: la imatge de la dona ha desaparegut; no en queda sinó un record simbòlic, a manera de condecoració i en forma de polseres, indici dels èxits de l'home en la seva "pesca d'altura» (ja que és un "pescador» internacional i cosmopolita, els noms gravats a les polseres s'encarreguen precisament de certificar-ho) i en el seu «navegar contra corrent» (fora dels marcs de la moral establerta, cosa que $f a$ de les seves empreses amoroses quelcom de més difícil i més divertit).

Si la dona sol identificar-se en els anuncis amb els perfums que uti- 
litza (núms. 4, 19, 20 i 31), l'objecte amb el qual més tendirà a identificar-se I'home és el cotxe. Dotat d'atributs virils, «aspecte aventurer», «capaç de qualsevol cosa» i, pet dzmunt de tot, «potent» (núm. 29), l'homecotxe vol ésser objecte d'«admitaciós per part de la dona, irresistiblement portada a «girar el cap» davant la seva aparició.

L'amant admirativa és també, com tota dona, una dona enjogassada, poc assenyada, una dona infantil, per a la qual tot forma part de l'immens joc que és la vida (num. 30). Ilespreocupada, inconscient, és la dona que té ganes de «fer follies», "coses insòlites» (núm. 31). Aquesta presència en la dona de l'element infantil farà que tornem a retrobar ací elements analitzats ja en parlar de la neria i la noia: la dona enjogassada és també la dona fràgil, delicada, que nexiessita protecció (masculina); la dona convertida en una joguina de l'home, el qual en fa a la vegada la seva propietat privada (núm. 32).

Aquesta paradoxal omnipresència de l'home en els anuncis publicitaris en què apareix la dona, té aparentment una sola excepció en aquells casos en què la dona apareix realment sola, realment amb si mateixa (núm. 33). És la dona que s'autocomplau, extasiada, centrada en si mateixa, acariciant-se elía mateixa. És la dona que s'autocontempla i que s'autoerotitza, en una mena de joc masturbatori al qual l'home sols hi té accés en la seva qualitat de vojeur $\mathrm{i}$, indirectament, en la mesura en què el fet mateix de petfumar-se dinota un afany de projecció cap a l'home.

\section{La dona-objecte decoratiu}

Una darrera categoria inclou finalment aquells anuncis en els quals la presència de la dona no cortespon a l'exercici de cap paper femení determinat, sino que obeeix a un pur criteri estètic. La dona en aquests casos és triada com un pur objecte decoratiu, però fóra perfectament substituible per d'altres objectes (vegeu per exemple el núm. 34).

\section{Conclusions}

L'estereotip de la dona que vehicula la publicitat és el resultat del conjunt de tots els papers que hem analitzat. Es important de fer notar, en efecte, que malgrat que els anuncis presentin imatges de la dona en etapes diferents de la seva vida i en l'exercici d'activitats diverses, no hi ha mai contradicció entre elles sinó que formen en definitiva un tot coherent $i$ 
únic. La dona dels anuncis publicitaris és sempre nena i noia a la vegada que adulta, de la mateixa manera que la nena i la noia són ja presentades amb les «qualitats» $\mathrm{i}$ 《virtuts» típicament femenines: la nena és una futuxa amant $i$ una esposa $i$ mare en potència, $i$ la dona segueix essent fràgil i enjogassada com una criatura. D'altra banda, aquesta dona dels anuncis publicitaris juga uns papers que són més acumulatius que excloents: segueix essent casolana encara que treballi, és al mateix temps amant, esposa i mare. Podem parlar, doncs, no de dones diferents sinó d'uns únics model $i$ estereotip de dona recreats $i$ transmesos pels anuncis publicitaris.

Dues són les caracteristiques fonamentais d'aquesta dona tal com ens és presentada a través d'una diversitat de situacions: la deliberada accentuació de la seva dimensió sexual i eròtica, i la seva sistemàtica subordinació a l'home. La dona dels anuncis és sempre bonica $i$ atractiva perquè, com dèiem al començament, forma part de l'embalatge del producte que la publicitat ens vol fer comprar. Cal, per tant, que faci goig, que cridi l'atenció, que sigui suggerent, que tingui appeal; i el més important de tots els appeal és, precisament, en la nostra societat, el sex appeal. Però al mateix temps aquesta dona atractiva és a la vegada una dona sotmesa $i$ subordinada a l'home. Aquest fet, que ha estat subratilat ja en el comentari a diferents anuncis, es $\mathrm{fa}$ particularment palès quan hom observa les postures físiques adoptades pels personatges, $\mathrm{i}$ en especial en els casos en què apareixen junts a un mateix anunci homes $i$ dones.

L'home és sistemàticament més alt que la dona, com un signe de superioritat $i$ de domini (nums. 3, 5, 6 i 22); fins $\mathrm{i}$ tot quan es tracta de nens ell és ja més alt que elia (núm. 2). ${ }^{13}$ L'home és presentat en els anuncis gairebé sempre dret, mentre que en la dona la verticalitat alterna amb les postures inclinades (num. 23) o simplement hoxizontals (números 21 i 24). Quan uns i altres apareixen drets, hom pot observar nogensmenys diferències significatives: rígid $i$ ben plantat ell, com qui controla $i$ domina la situació mentre que en la dona són típiques les flexions del cos i de les cames (nums. 3, 27 i 30). El mateix hom pot observar en les mirades: Lhome sol mirar recte davant d'ell, fredament, mentre que la dona sovint abaixa la mirada (núm. 5) o bé es contempla l'home, plena d'admiració (nums. 7, 22 i 29). La seriositat, habitual en l'home, contrasta amb la tendència de la dona a somtiure (nums. 15 i 22). Tots aquests elements convergeixen a donar de l'home una imatge de dominador, de control, d'estar

13. Aquesta sistemàtica diferència de postures i alçades permet que a diversos anuncis en què es presenten objectes (botelles, gots) llurs formes $\mathrm{i}$ alçades representin a la perfecció l'estereotip dels cossos masculí i femení. 


\section{A la mayoriade lagente}

mi diamante le dice que estoy comprometida. A mi me dice que estoy enamorada.
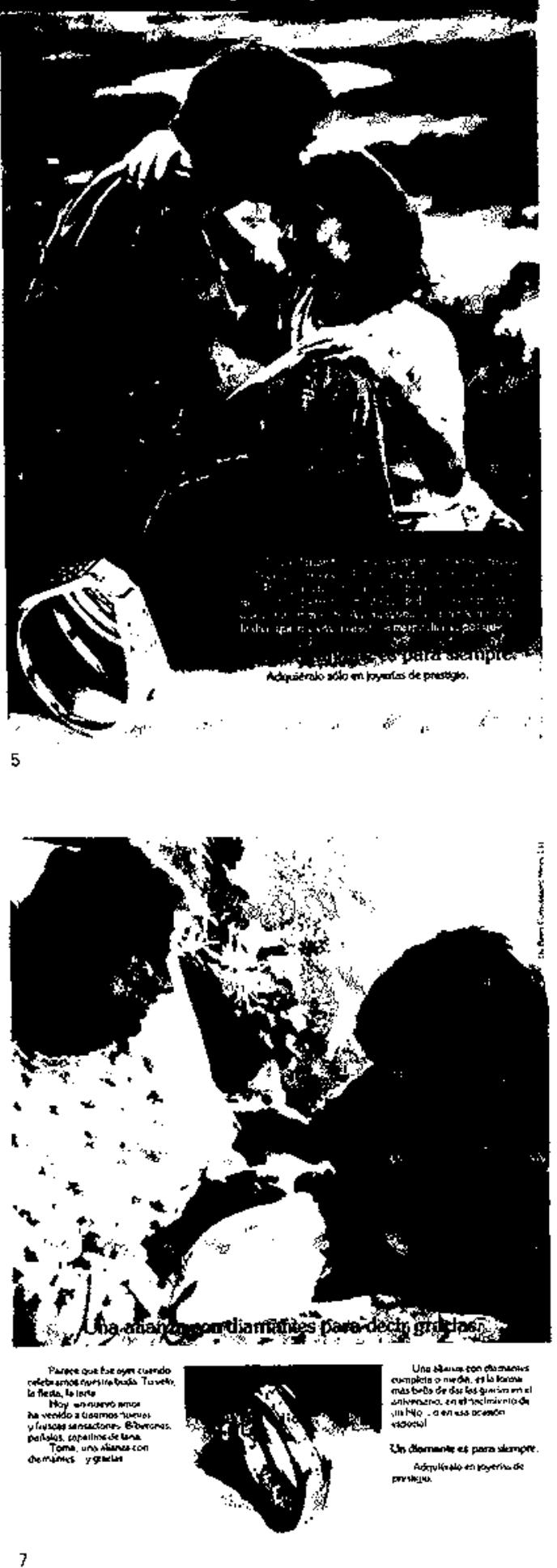

Eres de quien sabe ver H lona con fé y confianza

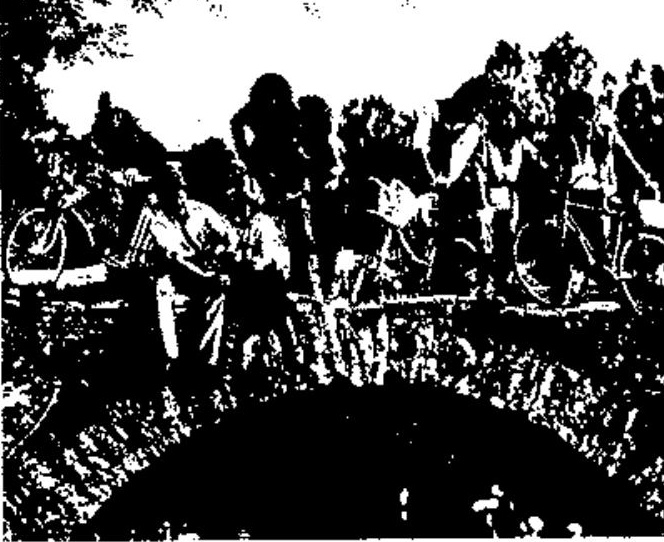

6

\section{Sé siempre tú misma.}

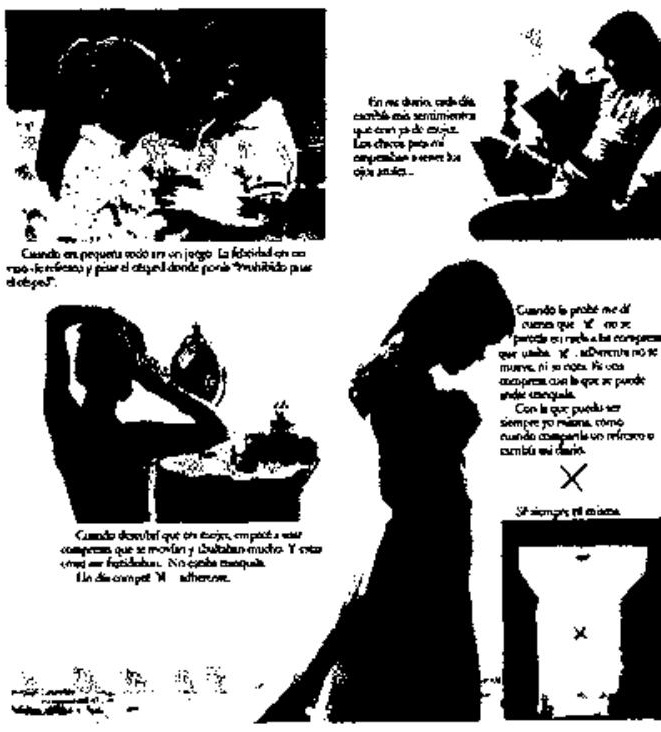




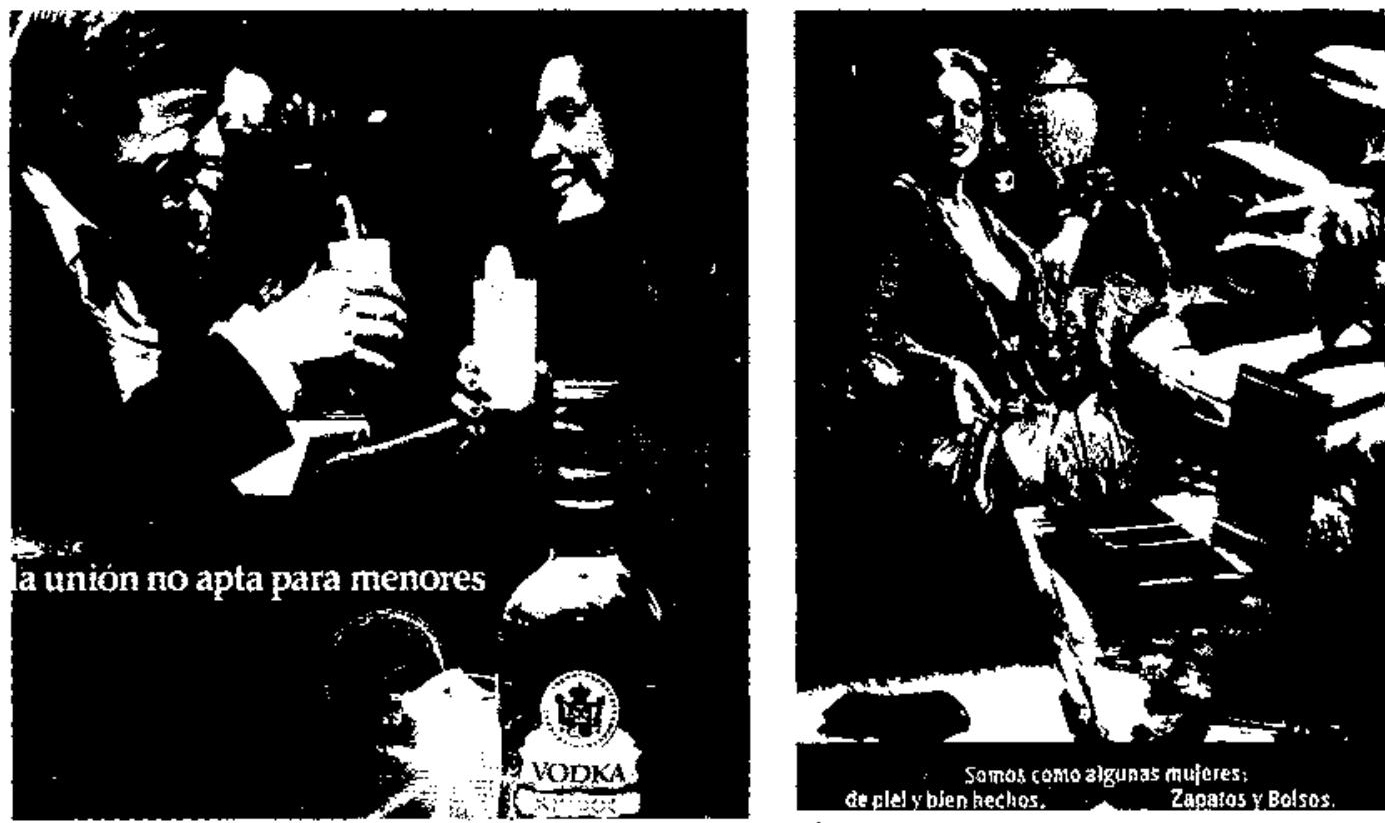

$x \times$, prendas muy excitantes.
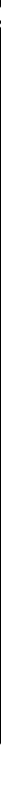



\section{¿cual prefieres tú?}

mientras sea $x \times \bar{x}$ cuatauerace ellos
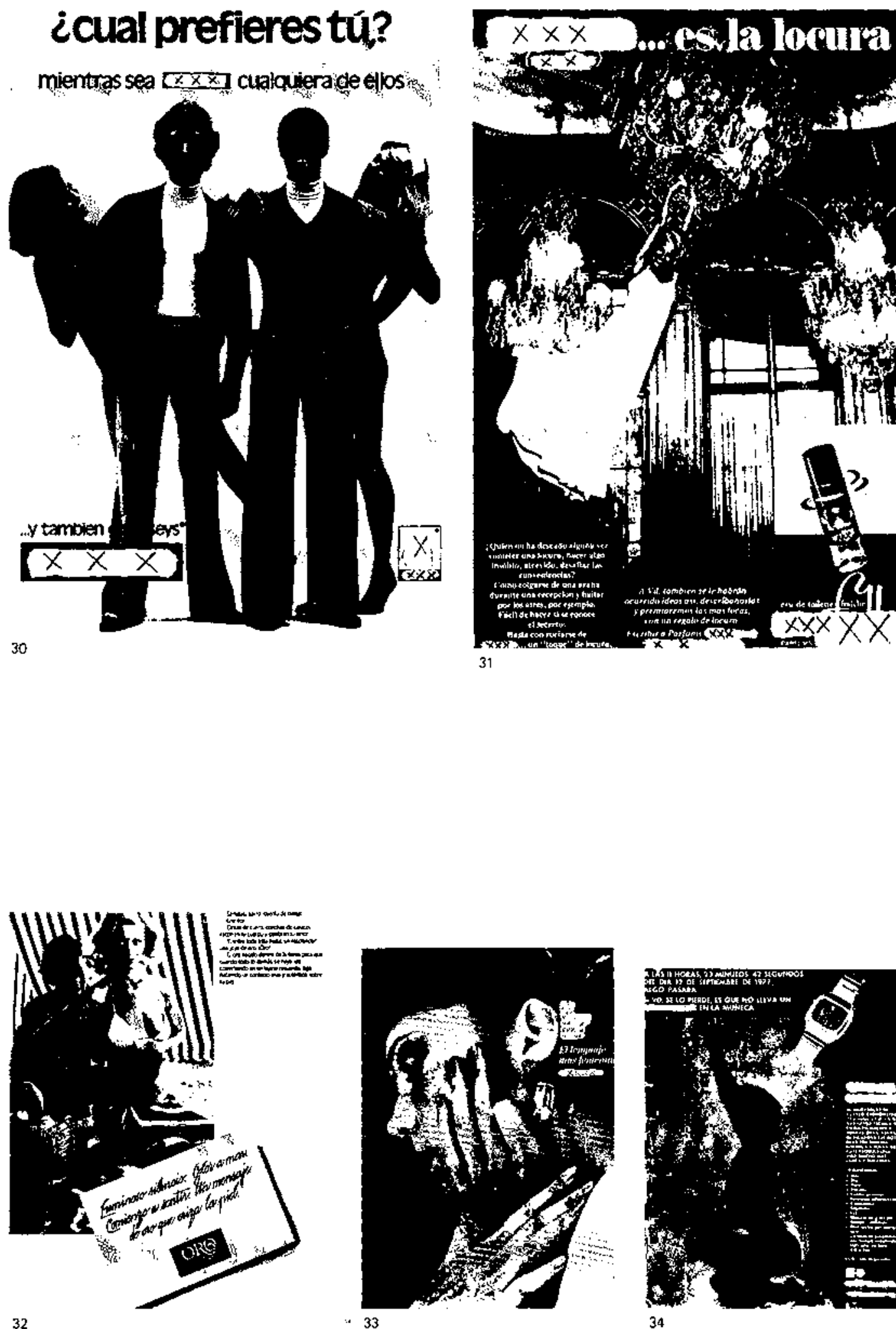

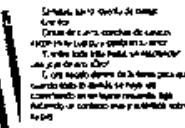

1.

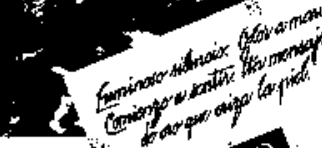
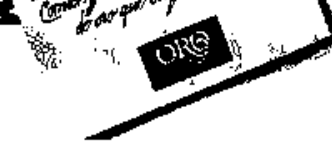

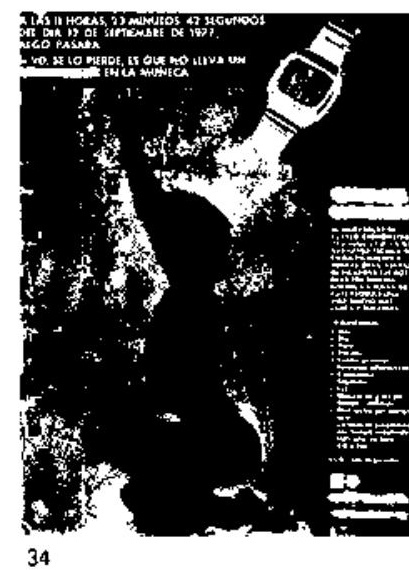


alerta, mentre la dona es permet d'abandonar-se, plena de confiança en ell (núm. 5).

Ens trobem en definitiva amb l'oposició ajudador/ajudada (núm. 6), ensenyant/ensenyada, dominador/dominada, prosector/protegida. La dona, en efecte, és presentada per la publicitat com la protegida de l'home, i això tant al nivell familiar, com en el professional i l'amorós (núms. 9, 15 i 32). Si la presència de la dona té com a finalitat la d'atreure la mirada, pel seu cos, la seva postura o la sevir vestimenta (o nuesa), l'home hi apareix en canvi com una manifestació de poder i de domini, sobre el món i sobre els altres.

La publicitat esdevé així ın element important de reforçament del procés de socialització, de fabricació de mascles i femelles, i de llurs diferències. La publicitat - -dèiem abans, i concloem ara- juga sociològicament una funció de reproducció de la ideologia dominant i de la moral establerta, a la vegada que contribueix a legitimar i a reforçar, gràcies a la seva extremada importància a la societat de consum, aqutzesta moral i aquesta ideologia.

JOAN ESTRUCH

Francesc MERCADÉ

JORDI ROMEU

Departament de Sociologia

Universitat Autònoma de Barcelona

Bellaterra

Barcelona 